\title{
Stress-Induced Hyperthermia in Translational Stress Research
}

\author{
Christiaan H. Vinkers ${ }^{*}, 1$, Renske Penning ${ }^{1}$, Marieke M. Ebbens ${ }^{1}$, Juliane Hellhammer ${ }^{2}$, \\ Joris C. Verster ${ }^{1}$, Cor J. Kalkman ${ }^{3}$ and Berend Olivier ${ }^{1,4}$
}

\author{
${ }^{I}$ Division of Pharmacology, Utrecht Institute for Pharmaceutical Sciences (UIPS) and Rudolf Magnus Institute of \\ Neuroscience, Utrecht University, Utrecht, The Netherlands \\ ${ }^{2}$ Daacro Clinical Research Organization, Trier, Germany \\ ${ }^{3}$ Department of Anesthesiology, University Medical Centre Utrecht, Utrecht, The Netherlands \\ ${ }^{4}$ Department of Psychiatry, Yale University School of Medicine, New Haven, CT, USA
}

\begin{abstract}
The stress-induced hyperthermia $(\mathrm{SIH})$ response is the transient change in body temperature in response to acute stress. This body temperature response is part of the autonomic stress response which also results in tachycardia and an increased blood pressure. So far, a SIH response has been found in a variety of species (including rodents, baboons, turtles, pigs, impalas and chimpanzees), and there are indications that stress exposure alters body temperature in humans. This review aims to assess the translational potential and the different aspects of the body temperature reaction in response to stress. If stress-induced temperature changes are consistent across species, the SIH paradigm may be employed in preclinical and clinical setups and provide a tool to examine the pharmacological, genetic and mechanistic background of stress at both the preclinical and the clinical level.
\end{abstract}

Keywords: Translational, autonomic nervous system, stress, anxiety model, emotional fever, menopausal hot flush.

\section{INTRODUCTION}

Animal models have significantly aided in establishing the biological basis of stress-related psychiatric disorders including anxiety disorders and depression [1]. However, any approach at both the preclinical and clinical level is valuable and may help identifying potentially effective new compounds before expensive clinical trials are initiated. The stress-induced hyperthermia (SIH) response is a relatively short-lasting rise in body temperature in response to stress which has been reported in rodents, baboons, sheep, impalas and chimpanzees (for review see [2]). In addition to nonhuman primate studies that report temperature changes after stress exposure such as increased tympanic membrane temperature in chimpanzees [3] and decreased nasal temperature of rhesus monkeys [4], there are also indications that stress exposure alters body temperature in human subjects $[5,6]$. Throughout this review, the SIH response is defined as the body temperature response in response to stress. Although the SIH response does not model any specific psychiatric condition, this response may be useful as a read-out parameter of stress. It can be studied at the preclinical and clinical level in different stressful experimental setups and may therefore serve as an animal-tohuman stress-related parameter. The present review therefore aims to assess the translational potential and the different aspects of the SIH paradigm. If exposure to stress reproducibly affects body temperature in humans and

*Address correspondence to this author at the Division of Pharmacology, Utrecht Institute for Pharmaceutical Sciences and Rudolf Magnus Institute of Neuroscience, Utrecht University, Sorbonnelaan 16, 3584CA Utrecht, The Netherlands; Tel: +31 (0) 30253 1599; Fax: +31 (0) 30253 7900;

E-mail: c.h.vinkers@uu.nl preclinical species, the SIH paradigm may be relevant for research into human stress-related disorders, including the assessment of putative stress-attenuating properties of drugs.

\section{HUMAN THERMOREGULATION}

Human body temperature is kept at a constant $37{ }^{\circ} \mathrm{C}$, ranging from 35.8 and $38.2{ }^{\circ} \mathrm{C}$ by regulating the balance between heat production and heat loss. It can be challenging to determine the 'normal' body temperature as this depends on the location of the temperature sensor on the body, time of day and measurement equipment [7]. A meta-analysis of Sund and co-workers reviewed 27 temperature studies and found different ranges for oral $\left(33.2-38.2{ }^{\circ} \mathrm{C}\right)$, rectal $(34.4-$ $37.8{ }^{\circ} \mathrm{C}$ ), tympanic $\left(35.4-37.8{ }^{\circ} \mathrm{C}\right)$ and axillary $(35.5-37.0$ $\left.{ }^{\circ} \mathrm{C}\right)$ temperatures [8]. There has been an ongoing debate which site of measurement most accurately reflects the true body temperature [9]. In rest, metabolically active organs such as the liver produce most heat, whereas during exercise, skeletal muscles account for heat production. Besides metabolic mechanisms, body temperature is regulated by environmental heat exchange. Different parts of the body have different temperatures, with the highest temperature in the brain and the organs in the thoracic and abdominal cavities (the central or 'core' temperature). In contrast, the body's shell, essentially the skin, usually has the lowest temperature (the peripheral temperature). The central temperature is precisely regulated by altering the peripheral temperature through heat exchange with blood. A high central temperature (e.g. after exercise) leads to increased capillary blood flow in the skin by opening arterial resistance vessels where it exchanges heat with the environment, leading to heat loss and a net increase of skin temperature. 
Body temperature regulation is a complex and vital process which is governed by the central nervous system. The hypothalamic preoptic area (POA) is the main thermoregulatory integrating center that contains a heat-loss center with warm-sensitive neurons and a heat-promoting center with cold-sensitive neurons. The hypothalamus receives input from peripheral thermoreceptors located in the skin and central thermoreceptors sensitive to blood temperature $[10,11]$. Warm-sensitive neurons inhibit coldresponsive neurons of the dorsomedial nucleus of the hypothalamus (DMH). After exposure to cold, activity of warm-sensitive neurons decreases and subsequently leads to heat conservation and/or heat production. DMH activation results in both vasoconstriction and shivering via neurons that project directly to the rostral raphe pallidus ( $\mathrm{RPa}$ ) (for reviews: [12, 13]). The $\mathrm{RPa}$ directly controls sympathetic preganglionic neurons in the intermediolateral cell column of the thoracic spinal cord $[14,15]$. In addition to autonomic processes, behavioral strategies (putting on warmer clothing, consumption of hot fluids) aids in keeping an optimal body temperature $[11,16,17]$.

Stress-induced changes in body temperature are probably mediated through hypothalamic pathways including the $\mathrm{DMH}$ and the RPa. However, as the SIH response is an acute stress response, it is probably initiated by limbic brain areas, including various amygdala nuclei [18]. In a recent study, we showed that the classical benzodiazepine diazepam but not the prostaglandin-blocking aspirin attenuated the SIH response in rodents, whereas aspirin but not diazepam greatly reduced LPS- and IL-1 $\beta$ induced fever states, suggesting that stress-induced hyperthermia and infectioninduced fever are two distinct processes [19].

\section{THE SIH RESPONSE IN HUMAN SUBJECTS}

A variety of studies investigated the effects of stress on body temperature in human subjects. Generally, these studies differ in the experimental setup, methodology and site of temperature measurement. In two early studies, the axillary temperature of 1068 and 1374 students was measured before their exams [20, 21]. Compared to a 'normal' body temperature of 37 degrees, the stress-induced body temperature significantly increased. Marazittti and coworkers conducted an investigation in which the axillary temperature was increased in 22 residents before an important exam as compared to an unstressed situation some weeks later [6]. In support, the oral temperature of 108 students was increased before a difficult exam compared to a non-stressful situation [5]. Interestingly, grade point averages increased with larger temperature increases. Male participants who watched or participated in a boxing contest displayed elevated oral temperatures compared to oral temperature levels on a regular school day [22]. In contrast to these studies, peripheral finger temperatures generally decrease in response to stress. In one study, finger temperature decreased up to $13,5{ }^{\circ} \mathrm{C}$ (!) in 45 out of 47 subjects in affective states, whereas only a slight increase of forehead and cheek temperature was observed in a minority of the subjects [23]. In support, listening to 'positive" music elevated skin temperature of the middle finger whereas 'negative' music decreased it [24]. Surprisingly, only music in the left ear induced these skin finger temperature responses [25]. We recently found that in healthy human subjects, upper arm skin temperature increased during exposure to the Trier Social Stress Test. Taken together, the existing human studies report that body temperature either rises or drops in response to stress depending on the stressinduction method, the body location and the temperature measuring apparatus. A tentative conclusion may be that axillary and oral temperature rise in response to stress, whereas distal skin temperature decreases in stressful situations as a result of vasoconstriction. Thus, different thermoregulatory reactions in response to stress may exist depending on the site of measurement. It can be hypothesized that the skin temperature in the distal parts of the limbs (e.g. fingers) reacts differently to stress compared to the more proximal skin temperature (e.g. axilla) or even the core body temperature.

\section{TRANSLATIONAL POTENTIAL OF THE SIH PARADIGM}

\subsection{Stress as a Translational Approach in Psychiatric Research}

Stress is an intuitively translational concept as any emotional or physical trigger will result in a physiological stress response in almost any organism [26]. In support, both preclinical and clinical studies suggest a pivotal role for the amygdala in stress [27-30]. Adaptive stress strategies exist in humans and animals that are beneficial for survival [31]. Moreover, the concept that the adaptive nature of stress (allostatic load) is not infinite and can lead to psychopathology when excessive or chronic stress is experienced possesses translational potential [32]. So far, a dysfunctional stress system has been suggested in different psychiatric disorders, among which anxiety disorders, depression and schizophrenia [33, 34].

\subsection{The Autonomic Stress Response in Translational Research}

Emotional and psychological stress has been shown to consistently activate the autonomic nervous system. This response is mediated by an increased activity of the sympatho-adrenomedullary system, resulting in increased heart rate and blood pressure, cutaneous vasoconstriction in the periphery of the limbs or selective dilatation elsewhere, redistribution of organ blood flow and increased cardiac output and an increase in (non-)shivering thermogenesis [18, 29, 33]. These responses are present across species, allowing a direct comparison between humans and animals [12, 29, 35-37]. Interestingly, environmental challenges induce a transient brain hyperthermia in the nucleus accumbens which is more rapid and stronger compared to muscle temperature, suggesting that central hyperthermia precedes subsequent body hyperthermia [38].

Organisms display individual differences in stress responsivity which are the result of genetic and environmental factors $[39,40]$. In rats, a distribution of SIH amplitude in response to novel cage stress exists [41], and the SIH amplitude also depends on stressor intensity [42]. Whether the SIH amplitude correlates with perceived stress levels in humans remains to be investigated. In rats, maternal deprivation leads to a higher $\mathrm{SIH}$ response at adult age [43], and repeated social stress exposure facilitated a larger $\mathrm{SIH}$ response compared to controls [44]. These studies support 
the notion that individual life experiences directly affect the $\mathrm{SIH}$ response later in life. Altogether, the stress-induced body temperature alterations seem to possess value as body temperature is consistently affected in a stressful situation, depends on stressor intensity and is sensitive to the effects of previous (early life) stressful experiences. There have been studies reporting stress-induced hypothermia rather than hyperthermia. Whether this hypothermia represents a unique response to stress or rather is a physiological effect is still subject to debate, and stress-induced hypothermia has been attributed to stressor type, anxiety levels, peripheral vasodilatation, ambient temperature [45].

\subsection{Efficacy of Anxiolytic Drugs in the SIH Paradigm}

A SIH response is present in all mammals that have been tested to date, including humans, chimpanzees, baboons, silver foxes, pigs, sheep, impalas, turtles, ducks, ground squirrels, rabbits, rats and mice [46-51]. In rodents, body temperature is usually determined by manual rectal temperature measurements or with telemetric equipment in the abdominal cavity. So far, the SIH has been particular useful as a screening approach to evaluate the efficacy of novel anxiolytic drug candidates [52]. Drug classes with clinically effective anxiolytic properties such as $\mathrm{GABA}_{\mathrm{A}}$ and $5-\mathrm{HT}_{1 \mathrm{~A}}$ receptor agonists as well as $\mathrm{CRF}_{1}$ receptor antagonists were all proven to attenuate the SIH response in animals [2, 53-56]. In contrast, non-anxiolytic dopaminergic or noradrenergic compounds as well as acute or chronic exposure to antidepressants generally do not alter the SIH response in preclinical species [2]. The discrepancy between clinical efficacy of selective serotonergic reuptake inhibitors (SSRIs) and tricyclic antidepressants (TCAs) vs. inefficacy in preclinical SIH studies may at least be partially explained by the fact that the SIH response generally constitutes a normal and healthy stress response. The drugs that have been found to reduce the $\mathrm{SIH}$ response (e.g. benzodiazepines), acutely do so irrespective of the healthy or pathological status of an individual. This way, one may argue that chronic exposure to SSRIs would only alter the SIH response under pathological conditions. So far, no study has been carried out to assess whether a standard anxiolytic drug (e.g. a classical benzodiazepine) alters the $\mathrm{SIH}$ response in human subjects. If drugs that exert acute anxiolytic effects such as a benzodiazepine reduce the SIH response in healthy subjects, this would yield a possible indicator of a drug's acute anxiolytic profile.

\subsection{Interpretation of the SIH Response}

The SIH response in itself does not model any disease but rather functions as a quantitative read-out of stress in any situation. Studies investigating dysfunctional body temperature responses are lacking, even though a reduced autonomic flexibility has been found in panic disorder and general anxiety disorder $[57,58]$. In all cases, it is vital that the SIH response should be contextually interpreted. For example, sexual activity [59] and aggression [60] both increase body temperature. Moreover, the opoid antagonist naloxon does not affect the $\mathrm{SIH}$ response in response to measuring the rectal temperature [61], but was effective in a footshock experiment [62]. In another study, dopamine receptor blockade fully reversed the central temperatureincreasing effects of cocaine, but only partially reversed the hyperthermic effects of tail-pinch and social interaction [63]. Also, the effects of drugs on basal body temperature can hamper the interpretation of SIH data. For example, the 5$\mathrm{HT}_{1 \mathrm{~A}}$ receptor agonist buspirone [64] and the $5-\mathrm{HT}_{2 \mathrm{C}}$ receptor agonist $\mathrm{mCPP}$ influence body temperature in human subjects $[65,66]$.

Putative anxiogenic drugs generally do not increase the autonomic SIH response in preclinical studies, suggesting that increased anxiety levels are not automatically accompanied by higher autonomic stress responsivity. Although anxiogenic compounds are considered to heighten subjective anxiety levels, tachycardia in anxious people depends on the situation and diagnosis, and a more avoiding personality is associated with reduced heart rate responses [67]. Moreover, patients with panic disorder (PD) display comparable physiological responses to healthy controls, even though they experience more frequent distress, suggesting that the perception of stress in anxiety disorders is not accompanied by heightened autonomic responses [58]. Also, administration of the anxiogenic $5 \mathrm{HT}_{2 \mathrm{C}}$ receptor agonist mCPP to patients with panic disorder or generalized anxiety disorder did not yield different physiological responses compared to controls, indicating the lack of autonomic hyperactivity of anxiogenic substances in anxiety disorders $[68,69]$. Together, these data suggest that increased subjective stress levels due to anxiogenic drugs may not necessarily be accompanied by increased autonomic stress responsivity, which is in line with the SIH literature so far.

\section{THE SIH RESPONSE AND BODY TEMPERATURE IN PATHOPHYSIOLOGY}

The role of body temperature in pathophysiology has received less attention. There is evidence for an altered thermoregulation or SIH response in various stress-related disorders. A series of articles by Shiloh et al. have suggested a dysfunctional thermoregulation in schizophrenia patients that corresponds to symptom severity [70-74]. Moreover, circadian body temperature abnormalities have been observed in depressive disorders [75], and there is evidence for a relationship between insomnia and body temperatures [76]. Interestingly, removal of the olfactory bulbs, an animal model of depression, results in rapid, stable and persistent changes in basal and stress-induced body temperature levels $[77,78]$. Also, perimenopausal women may experience hot flushes that are characterized by an acute rise in skin temperature which can be regarded as a form of SIH. In support, hot flushes are associated with anxiety and psychological factors $[79,80]$. There is evidence that a hot flush is caused by a narrowed band around the setpoint mediated by the hypothalamus $[81,82]$, or, alternatively, by increasing levels of norepinephrine and decreasing levels of serotonin due to declining estrogen levels after menopause [83-85].

\section{CONCLUSION}

A growing body of literature provides support to the existence of a human $\mathrm{SIH}$ response. The fact that a $\mathrm{SIH}$ response is consistently present across species in response to stress and can be studied at the preclinical and clinical level indicates that the SIH paradigm may prove to have translational value. However, studies investigating the human SIH response are scarce, and more research is needed 
to characterize the basal and stress-induced body temperature levels in humans. Nevertheless, current evidence suggests that the SIH paradigm may function as a translational approach to study the effects of stress in healthy human subjects as well as in different psychiatric disorders. In animals, anxiolytic drugs acutely reduce the SIH response. So far, no human studies have been carried out to examine anxiolytic drug effects on the SIH response in human subjects. If future studies prove that a SIH response in humans can be reduced by anxiolytic drugs, this would strengthen the role of the SIH paradigm in translational stress research.

\section{REFERENCES}

[1] Cryan, J.F.; Holmes, A. The ascent of mouse: advances in modelling human depression and anxiety. Nat. Rev. Drug Discov., 2005, 4, 775-790.

[2] Bouwknecht, J.A.; Olivier, B.; Paylor, R.E. The stress-induced hyperthermia paradigm as a physiological animal model for anxiety: a review of pharmacological and genetic studies in the mouse. Neurosci. Biobehav. Rev., 2007, 31, 41-59.

[3] Parr, L.; Hopkins, W. Brain temperature asymmetries and emotional perception in chimpanzees. Pan troglodytes. Physiol. Behav., 2000, 71, 363-371.

[4] Nakayama, K.; Goto, S.; Kuraoka, K.; Nakamura, K. Decrease in nasal temperature of rhesus monkeys (Macaca mulatta) in negative emotional state. Physiol. Behav., 2005, 84, 783-790.

[5] Briese, E. Emotional hyperthermia and performance in humans. Physiol. Behav., 1995, 58, 615-618.

[6] Marazziti, D.; Di Muro, A.; Castrogiovanni, P. Psychological stress and body temperature changes in humans. Physiol. Behav., 1992, 52, 393-395.

[7] Mackowiak, P. Normal 'body' temperature. In Fever. Basic Mechanisms and Management; Mackowiak, P.A., Ed.; Philadelphia, NY: Lippincott-Raven, 1997, pp. 207-213.

[8] Sund-Levander, M.; Forsberg, C.; Wahren, L.K. Normal oral, rectal, tympanic and axillary body temperature in adult men and women: a systematic literature review. Scand. J. Caring Sci., 2002, $16,122-128$.

[9] Craig, J.V.; Lancaster, G.A.; Taylor, S.; Williamson, P.R.; Smyth, R.L. Infrared ear thermometry compared with rectal thermometry in children: a systematic review. Lancet, 2002, 360, 603-609.

[10] Boulant, J.A. Role of the preoptic-anterior hypothalamus in thermoregulation and fever. Clin. Infect. Dis., 2000, 31(Suppl 5), S157-161.

[11] Marieb, E.; Hoehn, K. Human Anatomy \& Phsyiology; $7^{\text {th }}$ ed.; Pearson International Edition: San Francisco, 2007, p. 1195.

[12] DiMicco, J.A.; Sarkar, S.; Zaretskaia, M.V.; Zaretsky, D.V. Stressinduced cardiac stimulation and fever: common hypothalamic origins and brainstem mechanisms. Auton. Neurosci., 2006, 126127, 106-119.

[13] Dimicco, J.A.; Zaretsky, D.V. The dorsomedial hypothalamus: a new player in thermoregulation. Am. J. Physiol. Regul. Integr. Comp. Physiol., 2007, 292, R47-63.

[14] Nakamura, K.; Matsumura, K.; Hubschle, T.; Nakamura, Y.; Hioki, H.; Fujiyama, F.; Boldogkoi, Z.; Konig, M.; Thiel, H.J.; Gerstberger, R.; Kobayashi, S.; Kaneko, T. Identification of sympathetic premotor neurons in medullary raphe regions mediating fever and other thermoregulatory functions. J. Neurosci., 2004, 24, 5370-5380.

[15] Nakamura, K.; Matsumura, K.; Kobayashi, S.; Kaneko, T. Sympathetic premotor neurons mediating thermoregulatory functions. Neurosci. Res., 2005, 51, 1-8.

[16] Benarroch, E.E. Paraventricular nucleus, stress response, and cardiovascular disease. Clin. Auton. Res., 2005, 15, 254-263.

[17] Gale, C.C. Neuroendocrine aspects of thermoregulation. Annu. Rev. Physiol., 1973, 35, 391-430.

[18] Carrasco, G.A.; Van de Kar, L.D. Neuroendocrine pharmacology of stress. Eur. J. Pharmacol., 2003, 463, 235-272.

[19] Vinkers, C.H.; Groenink, L.; van Bogaert, M.J.; Westphal, K.G.; Kalkman, C.J.; van Oorschot, R.; Oosting, R.S.; Olivier, B.; Korte, S.M. Stress-induced hyperthermia and infection-induced fever: two of a kind? Physiol. Behav., 2009, 98, 37-43.
[20] Gotsev, T.; Ivanov, A. Psychogenic elevation of body temperature in healthy persons. Acta Physiol. Hung., 1950, 1, 53-62.

[21] Gotsev, T.; Ivanov, A. Elevation of body temperature in students during examinations. Acta Physiol. Hung., 1954, 6, 427-431.

[22] Renbourn, E.T. Body temperature and pulse rate in boys and young men prior to sporting contests. A study of emotional hyperthermia: with a review of the literature. J. Psychosom. Res., 1960, 4, 149175.

[23] Mittelmann, B.; Wolff, H. Affective states and skin temperature: experimental study of subjects with "cold hands" and Raynaud's syndrome. Psychosomatic Med., 1939, 1, 271-292.

[24] McFarland, R. Relationship of skin temperature changes to the emotions accompanying music. Biofeedback Self Regul., 1985, 10, 255-267.

[25] McFarland, R.A.; Kennison, R. Asymmetry in the relationship between finger temperature changes and emotional state in males. Biofeedback Self Regul., 1989, 14, 281-290.

[26] Herman, J. P.; Cullinan, W.E. Neurocircuitry of stress: central control of the hypothalamo-pituitary-adrenocortical axis. Trends Neurosci., 1997, 20, 78-84.

[27] Dayas, C.V.; Buller, K. M.; Day, T.A. Neuroendocrine responses to an emotional stressor: evidence for involvement of the medial but not the central amygdala. Eur. J. Neurosci., 1999, 11, 2312-2322.

[28] Myint, A.M.; O'Mahony, S.; Kubera, M.; Kim, Y.K.; Kenny, C.; Kaim-Basta, A.; Steinbusch, H.W.; Leonard, B.E. Role of paroxetine in interferon-\{alpha\}-induced immune and behavioural changes in male Wistar rats. J. Psychopharmacol., 2007, 21, 843850 .

[29] Ulrich-Lai, Y.M.; Herman, J.P. Neural regulation of endocrine and autonomic stress responses. Nat. Rev. Neurosci., 2009, 10, 397409.

[30] Davis, M. Neurobiology of fear responses: the role of the amygdala. J. Neuropsychiat. Clin. Neurosci., 1997, 9, 382-402.

[31] Korte, S.M.; Koolhaas, J.M.; Wingfield, J.C.; McEwen, B.S. The Darwinian concept of stress: benefits of allostasis and costs of allostatic load and the trade-offs in health and disease. Neurosci. Biobehav. Rev., 2005, 29, 3-38.

[32] Joels, M.; Baram, T.Z. The neuro-symphony of stress. Nat. Rev. Neurosci., 2009, 10, 459-466.

[33] de Kloet, E.R.; Joels, M.; Holsboer, F. Stress and the brain: from adaptation to disease. Nat. Rev. Neurosci., 2005, 6, 463-475.

[34] Roozendaal, B.; McEwen, B.S.; Chattarji, S. Stress, memory and the amygdala. Nat. Rev. Neurosci., 2009, 10, 423-433.

[35] Kuwaki, T.; Zhang, W.; Nakamura, A.; Deng, B.S. Emotional and state-dependent modification of cardiorespiratory function: role of orexinergic neurons. Auton. Neurosci., 2008, 142, 11-16.

[36] Franzini, C.; Lenzi, P.; Cianci, T. Interactions between temperature regulation and emotional arousal in the rabbit. Exp. Brain Res., 1981, 43, 87-92.

[37] Horiuchi, J.; McDowall, L.M.; Dampney, R.A. Differential control of cardiac and sympathetic vasomotor activity from the dorsomedial hypothalamus. Clin. Exp. Pharmacol. Physiol., 2006, 33, 1265-1268.

[38] Kiyatkin, E.A.; Brown, P.L.; Wise, R.A. Brain temperature fluctuation: a reflection of functional neural activation. Eur. J. Neurosci., 2002, 16, 164-168.

[39] Fyer, A.J.; Hamilton, S.P.; Durner, M.; Haghighi, F.; Heiman, G.A.; Costa, R.; Evgrafov, O.; Adams, P.; de Leon, A.B.; Taveras, N.; Klein, D.F.; Hodge, S.E.; Weissman, M.M.; Knowles, J.A. A third-pass genome scan in panic disorder: evidence for multiple susceptibility loci. Biol. Psychiatry, 2006, 60, 388-401.

[40] Hettema, J.M.; Neale, M.C.; Kendler, K.S. A review and metaanalysis of the genetic epidemiology of anxiety disorders. Am. $J$. Psychiatry, 2001, 158, 1568-1578.

[41] Vinkers, C.H.; van Bogaert, M.J.; Klanker, M.; Korte, S.M.; Oosting, R.; Hanania, T.; Hopkins, S.C.; Olivier, B.; Groenink, L. Translational aspects of pharmacological research into anxiety disorders: the stress-induced hyperthermia $(\mathrm{SIH})$ paradigm. Eur. J. Pharmacol., 2008, 585, 407-425.

[42] van Bogaert, M.J.; Groenink, L.; Oosting, R.S.; Westphal, K.G.; van der Gugten, J.; Olivier, B. Mouse strain differences in autonomic responses to stress. Genes Brain Behav., 2006, 5, 139149.

[43] Ito, A.; Kikusui, T.; Takeuchi, Y.; Mori, Y. Effects of early weaning on anxiety and autonomic responses to stress in rats. Behav. Brain Res., 2006, 171, 87-93. 
[44] Bhatnagar, S.; Vining, C.; Iyer, V.; Kinni, V. Changes in hypothalamic-pituitary-adrenal function, body temperature, body weight and food intake with repeated social stress exposure in rats. J. Neuroendocrinol., 2006, 18, 13-24.

[45] McGivern, R.F.; Zuloaga, D.G.; Handa, R.J. Sex differences in stress-induced hyperthermia in rats: restraint vs confinement. Physiol. Behav., 2009, 98, 416-420.

[46] Meyer, L.C.; Fick, L.; Matthee, A.; Mitchell, D.; Fuller, A. Hyperthermia in captured impala (Aepyceros melampus): a fright not flight response. J. Wildl. Dis., 2008, 44, 404-416.

[47] Gray, D.A.; Maloney, S.K.; Kamerman, P.R. Restraint increases afebrile body temperature but attenuates fever in Pekin ducks (Anas platyrhynchos). Am. J. Physiol. Regul. Integr. Comp. Physiol., 2008, 294, R1666-R1671.

[48] Bouwknecht, A.J.; Olivier, B.; Paylor, R.E. The stress-induced hyperthermia paradigm as a physiological animal model for anxiety: a review of pharmacological and genetic studies in the mouse. Neurosci. Biobehav. Rev., 2007, 31, 41-59.

[49] Cabanac, M.; Bernieri, C. Behavioral rise in body temperature and tachycardia by handling of a turtle (Clemmys insculpta). Behav. Processes, 2000, 49, 61-68.

[50] Ritter, M.J.; Ellis, M.; Anderson, D.B.; Curtis, S.E.; Keffaber, K.K.; Killefer, J.; McKeith, F.K.; Murphy, C.M.; Peterson, B.A. Effects of multiple concurrent stressors on rectal temperature, blood acid-base status, and longissimus muscle glycolytic potential in market-weight pigs. J. Anim. Sci., 2009, 87, 351-362.

[51] Pedernera-Romano, C.; Ruiz de la Torre, J.L.; Badiella, L.; Manteca, X. Effect of perphenazine enanthate on open-field test behaviour and stress-induced hyperthermia in domestic sheep. Pharmacol. Biochem. Behav., 2010, 94, 329-332.

[52] Vinkers, C.H.; Klanker, M.; Groenink, L.; Korte, S.M.; Cook, J.M.; Van Linn, M.L.; Hopkins, S.C.; Olivier, B. Dissociating anxiolytic and sedative effects of GABAAergic drugs using temperature and locomotor responses to acute stress. Psychopharmacology (Berl), 2009, 204, 299-311.

[53] Olivier, B.; Bouwknecht, J.A.; Pattij, T.; Leahy, C.; van Oorschot, R.; Zethof, T.J. GABAA-benzodiazepine receptor complex ligands and stress-induced hyperthermia in singly housed mice. Pharmacol. Biochem. Behav., 2002, 72, 179-188.

[54] Olivier, B.; Zethof, T.; Pattij, T.; van Boogaert, M.; van Oorschot, R.; Leahy, C.; Oosting, R.; Bouwknecht, A.; Veening, J.; van der Gugten, J.; Groenink, L., Stress-induced hyperthermia and anxiety: pharmacological validation. Eur. J. Pharmacol., 2003, 463(1-3), 117-132.

[55] Spooren, W.P.; Schoeffter, P.; Gasparini, F.; Kuhn, R.; Gentsch, C. Pharmacological and endocrinological characterisation of stressinduced hyperthermia in singly housed mice using classical and candidate anxiolytics (LY314582, MPEP and NKP608). Eur. J. Pharmacol., 2002, 435, 161-170.

[56] Griebel, G.; Simiand, J.; Steinberg, R.; Jung, M.; Gully, D.; Roger, P.; Geslin, M.; Scatton, B.; Maffrand, J. P.; Soubrie, P. 4-(2-Chloro-4methoxy-5-methylphenyl)-N-[(1S)-2-cyclopropyl-1-(3-fluoro-4- methylphenyl)ethyl]5-methyl-N-(2-propynyl)-1, 3-thiazol-2-amine hydrochloride (SSR125543A), a potent and selective corticotrophin-releasing factor(1) receptor antagonist. II. Characterization in rodent models of stress-related disorders. J. Pharmacol. Exp. Ther., 2002, 301, 333-345.

[57] Stockmeier, C.A.; Howley, E.; Shi, X.; Sobanska, A.; Clarke, G.; Friedman, L.; Rajkowska, G. Antagonist but not agonist labeling of serotonin-1A receptors is decreased in major depressive disorder. $J$. Psychiatr. Res., 2009, 43, 887-894.

[58] Hoehn-Saric, R.; McLeod, D.R.; Funderburk, F.; Kowalski, P. Somatic symptoms and physiologic responses in generalized anxiety disorder and panic disorder: an ambulatory monitor study. Arch. Gen. Psychiatry, 2004, 61, 913-921.

[59] Retana-Marquez, S.; Bonilla-Jaime, H.; Vazquez-Palacios, G.; Martinez-Garcia, R. Naltrexone effects on male sexual behavior, corticosterone, and testosterone in stressed male rats. Physiol. Behav., 2009, 96, 333-342.

[60] Caramaschi, D.; de Boer, S.F.; Koolhaas, J.M. Is hyperaggressiveness associated with physiological hypoarousal? A comparative study on mouse lines selected for high and low aggressiveness. Physiol. Behav., 2008, 95, 591-598.

[61] Lecci, A.; Borsini, F.; Volterra, G.; Meli, A. Pharmacological validation of a novel animal model of anticipatory anxiety in mice. Psychopharmacology (Berl), 1990, 101, 255-261.
[62] Millan, M.J.; Przewlocki, R.; Jerlicz, M.; Gramsch, C.; Hollt, V.; Herz, A. Stress-induced release of brain and pituitary betaendorphin: major role of endorphins in generation of hyperthermia, not analgesia. Brain Res., 1981, 208, 325-338.

[63] Kiyatkin, E.A. Brain temperature responses to salient stimuli persist during dopamine receptor blockade despite a blockade of locomotor responses. Pharmacol. Biochem. Behav., 2008, 91, 233242 .

[64] Navines, R.; Martin-Santos, R.; Gomez-Gil, E.; Martinez de Osaba, M.J.; Imaz, M.L.; Gasto, C. Effects of citalopram treatment on hypothermic and hormonal responses to the 5-HT1A receptor agonist buspirone in patients with major depression and therapeutic response. Psychoneuroendocrinology, 2007, 32, 411-416.

[65] Ghaziuddin, N.; Welch, K.; Greden, J. Central serotonergic effects of m-chlorophenylpiperazine (mCPP) among normal control adolescents. Neuropsychopharmacology, 2003, 28, 133-139.

[66] Quested, D.J.; Sargent, P.A.; Cowen, P.J. SSRI treatment decreases prolactin and hyperthermic responses to mCPP. Psychopharmacology (Berl), 1997, 133, 305-308.

[67] Hofmann, S.G.; Newman, M.G.; Ehlers, A.; Roth, W.T Psychophysiological differences between subgroups of social phobia. J. Abnorm. Psychol., 1995, 104, 224-231.

[68] van der Wee, N.J.; Fiselier, J.; van Megen, H.J.; Westenberg, H.G. Behavioural effects of rapid intravenous administration of metachlorophenylpiperazine in patients with panic disorder and controls. Eur. Neuropsychopharmacol., 2004, 14, 413-417.

[69] Van Veen, J.F.; Van der Wee, N.J.; Fiselier, J.; Van Vliet, I.M.; Westenberg, H.G. Behavioural effects of rapid intravenous administration of meta-chlorophenylpiperazine (m-CPP) in patients with generalized social anxiety disorder, panic disorder and healthy controls. Eur. Neuropsychopharmacol., 2007, 17, 637-642.

[70] Shiloh, R.; Weizman, A.; Stryjer, R.; Kahan, N.; Waitman, D.A. Altered thermoregulation in ambulatory schizophrenia patients: a naturalistic study. World J. Biol. Psychiatry, 2009, 10, 163-170.

[71] Shiloh, R.; Schapir, L.; Bar-Ziv, D.; Stryjer, R.; Konas, S.; Louis, R.; Hermesh, H.; Munitz, H.; Weizman, A.; Valevski, A. Association between corneal temperature and mental status of treatmentresistant schizophrenia inpatients. Eur. Neuropsychopharmacol. 2009, 19(9), 654-658.

[72] Shiloh, R.; Kushnir, T.; Gilat, Y.; Gross-Isseroff, R.; Hermesh, H.; Munitz, H.; Stryjer, R.; Weizman, A.; Manor, D. In vivo occipitalfrontal temperature-gradient in schizophrenia patients and its possible association with psychopathology: a magnetic resonance spectroscopy study. Eur. Neuropsychopharmacol., 2008, 18, 557564.

[73] Shiloh, R.; Munitz, H.; Stryjer, R.; Weizman, A. A significant correlation between ward temperature and the severity of symptoms in schizophrenia inpatients--a longitudinal study. Eur. Neuropsychopharmacol., 2007, 17, 478-482.

[74] Shiloh, R.; Munitz, H.; Portuguese, S.; Gross-Isseroff, R.; Sigler, M.; Bodinger, L.; Katz, N.; Stryjer, R.; Hermesh, H.; Weizman, A. Corneal temperature in schizophrenia patients. Int. J. Neuropsychopharmacol., 2005, 8, 537-547.

[75] Daimon, K.; Yamada, N.; Tsujimoto, T.; Takahashi, S. Circadian rhythm abnormalities of deep body temperature in depressive disorders. J. Affect. Disord., 1992, 26, 191-198.

[76] Lack, L.C.; Gradisar, M.; Van Someren, E.J.; Wright, H.R. Lushington, $\mathrm{K}$. The relationship between insomnia and body temperatures. Sleep Med. Rev., 2008, 12, 307-317.

[77] Vinkers, C.H.; Breuer, M.E.; Westphal, K.G.; Korte, S.M.; Oosting, R.S.; Olivier, B.; Groenink, L. Olfactory bulbectomy induces rapid and stable changes in basal and stress-induced locomotor activity, heart rate and body temperature responses in the home cage. Neuroscience, 2009, 159, 39-46.

[78] Roche, M.; Harkin, A.; Kelly, J.P. Chronic fluoxetine treatment attenuates stressor-induced changes in temperature, heart rate, and neuronal activation in the olfactory bulbectomized rat. Neuropsychopharmacology, 2007, 32, 1312-1320.

[79] Blumel, J.E.; Castelo-Branco, C.; Cancelo, M.J.; Cordova, A.T.; Binfa, L.E.; Bonilla, H.G.; Munoz, I.G.; Vergara, V.G.; Sarra, S.C. Relationship between psychological complaints and vasomotor symptoms during climacteric. Maturitas, 2004, 49, 205-210.

[80] Freeman, E.W.; Sammel, M.D.; Lin, H.; Gracia, C.R.; Kapoor, S.; Ferdousi, T. The role of anxiety and hormonal changes in menopausal hot flashes. Menopause, 2005, 12, 258-266. 
[81] Rapkin, A.J. Vasomotor symptoms in menopause: physiologic condition and central nervous system approaches to treatment. Am. J. Obstet. Gynecol., 2007, 196, 97-106.

[82] Sturdee, D.W.; Wilson, K.A.; Pipili, E.; Crocker, A.D. Physiological aspects of menopausal hot flush. Br. Med. J., 1978, 2, 79-80.

[83] Freedman, R.R. Hot flashes: behavioral treatments, mechanisms, and relation to sleep. Am. J. Med., 2005, 118(Suppl 12B), 124-130.
[84] Carpenter, J.S.; Gilchrist, J.M.; Chen, K.; Gautam, S.; Freedman, R.R. Hot flashes, core body temperature, and metabolic parameters in breast cancer survivors. Menopause, 2004, 11, 375-381.

[85] Freedman, R.R. Core body temperature variation in symptomatic and asymptomatic postmenopausal women: brief report. Menopause, 2002, 9, 399-401.

(C) Vinkers et al.; Licensee Bentham Open.

This is an open access article licensed under the terms of the Creative Commons Attribution Non-Commercial License (http://creativecommons.org/licenses/by$\mathrm{nc} / 3.0 /$ ) which permits unrestricted, non-commercial use, distribution and reproduction in any medium, provided the work is properly cited. 